\title{
Perfil nutricional e fatores associados ao baixo peso e à redução do consumo alimentar em crianças hospitalizadas
} Nutritional profile and factors associaed with low body weight and reduction of food intake in hospitalized children

Camila Neves Rodrigues* Carla de Oliveira Barbosa Rosa** Sônia Machado Rocha Ribeiro** Carolina Araújo dos Santos** Heloísa Helena Firmino**

\begin{abstract}
Resumo
A avaliação do estado nutricional de crianças hospitalizadas assume um papel fundamental na identificação precoce de riscos nutricionais. Assim, é de grande relevância identificar variáveis que exercem impacto no estado nutricional e na aceitação dos alimentos no ambiente hospitalar. O objetivo do trabalho foi avaliar o perfil nutricional de crianças internadas em um hospital e analisar as variáveis que exercem influência no diagnóstico nutricional e no consumo alimentar durante a hospitalização. O estado nutricional foi avaliado por meio da aferição de peso, comprimento/estatura, cálculo do Índice de Massa Corporal e avaliação dos índices antropométricos. A avaliação bioquímica foi realizada a partir das informações disponíveis no prontuário clínico. Os dados socioeconômicos, alimentares, de aleitamento materno e avaliação da aceitação das refeições oferecidas foram coletados por meio de aplicação de um questionário ao responsável pela criança. Participaram do estudo 208 crianças, sendo 61,5\% do sexo masculino e mediana de idade de 21,5(6-59) meses. Quanto ao estado nutricional, 80\% das crianças foram classificadas como eutróficas, 10\% apresentavam magreza e $10 \%$ excesso de peso. As crianças com baixo peso tiveram mais linfocitopenia $(p=0,038)$ e também foram as que apresentaram menor tempo de aleitamento materno exclusivo $(p=0,015)$. As crianças que apresentaram concentrações elevadas de PCR e leucócitos apresentaram baixa aceitação da dieta oferecida ( $p=0,034$ e $p=0,040$, respectivamente). Foram identificados fatores que se associaram ao baixo peso e a menor aceitação das refeições pelas crianças. Assim, atenção específica deve ser dada àquelas com alteração do estado inflamatório e com menor tempo de aleitamento materno exclusivo.
\end{abstract}

Palavras-chave: Avaliação nutricional. Pediatria. Ingestão de alimentos. Hospitalização.

\begin{abstract}
The evaluation of nutritional status in hospitalized children plays a critical role in the early identification of nutritional risk. Thus, it is of great importance to identify variables that have an impact on nutritional status and acceptance of food in the hospital environment. The objective of this work to evaluate the nutritional status of hospitalized children, the variables that influence the nutritional diagnosis and food intake during hospitalization. Nutritional status was evaluated by measurement of weight, length / height, body mass index and anthropometric indices. The biochemical evaluation was performed based on the information available in the medical record. Socioeconomic, dietary and breastfeeding data and, evaluation of the acceptance of meals offered were obtained through a questionnaire to the responsable for the children. The study included 208 children, predominantly male (61.5\%) and median age of 21.5 (6-59) months. In relation to nutritional status, $80 \%$ of children were classified eutrophic, $10 \%$ were thinness and $10 \%$ overweight. Children with low weight had more cases of lymphocytopenia $(p=0.038)$ and were also those who had shorter time of exclusive breastfeeding ( $p=0.015)$. Children with elevated concentrations of PCR and leukocytes showed low acceptance of the offered diet ( $p=0.034$ and $p=0.040$, respectively). Factors associated with low weight and lower acceptance of meals by children were identified. Particular attention should be given to children with altered inflammatory status and shorter time of exclusive breastfeeding.
\end{abstract}

Keywords: Nutrition Assessment. Pediatrics. Eating. Hospitalization.

DOI: 10.15343/0104-7809.201640016172

\footnotetext{
* Universidade Federal de Viçosa (Ex-Bolsista de Iniciação Científica do CNPQ), Viçosa-MG, Brasil. E-mail: camila.n.rodrigues@ufv.br

** Universidade Federal de Viçosa, Viçosa-MG, Brasil.

Os autores declaram não haver conflitos de interesse.
} 


\section{INTRODUÇÃO}

Apesar da redução na prevalência de desnutrição em crianças menores de cinco anos no mundo, ainda se observa elevados números neste grupo etário quando hospitalizadas, cerca de $40 \% 1$. Em países como a Alemanha, França, Reino Unido, Holanda, Brasil e Turquia, foram registradas prevalências que se situam entre $11 \%$ e $50 \%$ de desnutrição em crianças internadas $\mathrm{s}^{2,3}$. A desnutrição compromete $\mathrm{O}$ sistema imunológico, facilitando a instalação de infecções, assim como os processos infecciosos podem contribuir também para comprometimento do estado nutricional; a desnutrição representa, ainda, graves consequências a curto e longo prazo para a criança. Ao considerarmos o âmbito hospitalar, o estado nutricional influencia adversamente na evolução clínica ${ }^{4}$.

Assim, para um bom tratamento clínico deve-se atentar ao cuidado nutricional. A falta de uma avaliação nutricional adequada do paciente que ingressa e permanece no hospital, dificulta o seu diagnóstico, tratamento e compromete o prognóstico. Como a terapêutica nutricional varia conforme a doença de base, a avaliação nutricional assume papel importante não somente no momento da admissão, mas também durante todo período de hospitalização $0^{5,6,7}$.

Uma atenção crescente tem sido dada a avaliação do estado nutricional das crianças internadas, já que esta é considerada um dos melhores indicadores de saúde principalmente com relação a este grupo etário. O crescimento e o desenvolvimento infantil estão em grande parte condicionados pela alimentação e nutrição, além de serem muito sensíveis a alterações perante situações de infecções ou de privação nutricional².

Na prática hospitalar a avaliação nutricional subjetiva global (ASG) é muito utilizada para a triagem de risco e avaliação do estado nutricional, pois é um método simples, de baixo custo e não invasivo, podendo ser realizado à beira do leito ${ }^{8}$. Este é um instrumento aplicado e estudado predominantemente para população adulta, no entanto, nos últimos anos estudos tem sido voltados também para população pediátrica, porém tais evidências ainda são escassas ${ }^{9}$.

Assim apesar das evidências serem limitadas nessa área, hoje há alguns instrumentos que avaliam risco nutricional para pediatria, sendo que os principais são Pediatric Nutritional Risk Score (PNRS), Subjective Global Nutrition Assesment (SGNA), Screening Tool for the Assessment of Malnutrition in Pediatrics (STAMP) e STRONGkid. Destes, o instrumento STRONkids tem sido considerado mais prático e fácil de ser aplicado ${ }^{9}$. Silva e Tiengo ${ }^{10}$ ao avaliar o estado nutricional de crianças hospitalizadas através de medidas antropométricas e o instrumento de risco nutricional STRONkid, incluindo 148 crianças de 0 a 14 anos, ressaltou que medidas antropométricas são bons parâmetros para se avaliar, mas é necessário associar aos métodos subjetivos da avalição de risco nutricional.

Contudo um único método isoladamente não transmite uma resposta segura para avaliação do estado nutricional, sendo necessário um conjunto de métodos de investigação, como história clínica e alimentar, dados socioeconômicos e parâmetros bioquímicos. Tais são necessários para se obter melhores resultados ao nível de avaliação e identificação de qualquer situação de risco nutricional ${ }^{2,11}$.

Portanto, o diagnóstico nutricional, bem como o acompanhamento de sua evolução em crianças hospitalizadas assume um papel fundamental para um melhor planejamento de ações, a fim de minimizar qualquer risco nutricional, e, assim proporcionar a estes um melhor prognóstico. Identificar as variáveis que se associam a desvios nutricionais e que influenciem a aceitação dos alimentos consumidos durante a hospitalização assume relevante importância uma vez que possibilita a identificação de crianças potencialmente de maior risco.

Assim, este estudo teve como objetivo avaliar o perfil nutricional de crianças internadas em um hospital de ensino da cidade de ViçosaMG e associar variáveis à desvios nutricionais e à menor aceitação do consumo alimentar durante a hospitalização.

\section{MATERIAIS E MÉTODOS}


População

Trata-se de um estudo transversal analítico, no qual foram avaliadas as crianças internadas na pediatria de um hospital universitário, no período de dezembro de 2013 a julho de 2014. O estudo foi aprovado pelo Comitê de Ética em Pesquisa com Seres Humanos da Universidade Federal de Viçosa (registro n. 473.733 de acordo com a resolução CNS466/2012). A participação foi espontânea e voluntária, após os responsáveis legais pela criança terem sido esclarecidos sobre a pesquisa e assinarem o Termo de Consentimento Livre e Esclarecido, sendo-lhes também livre a opção de abandonar o estudo quando desejassem.

\section{Dados Antropométricos}

A avaliação antropométrica foi realizada por meio de aferição de peso e comprimento/ estatura em todas as crianças e adolescentes. Em crianças menores de dois anos o peso corporal foi aferido sem roupas em balança digital do tipo pesa-bebê (Balmak, modelo ELP-25BB), com capacidade de $25 \mathrm{~kg}$ e sensibilidade de $5 \mathrm{~g}$, e seu comprimento aferido em decúbito dorsal sobre uma superfície plana, com a utilização de um infantômetro, com escala em centímetros e capacidade máxima de $1 \mathrm{~m}$, sempre com a ação conjunta de dois examinadores para garantir o posicionamento da cabeça e afixação de ambos os pés. As crianças acima de dois anos e adolescentes foram pesadas com o mínimo de roupas, em balança mecânica tipo adulto (Welky-Indústria e comércio LTDA, modelo R-110), com capacidade máxima de 150 kg e precisão de $100 \mathrm{~g}$. A altura foi aferida com a criança em pé, utilizou-se o estadiômetro Portátil AlturaExata com escala métrica, em centímetros, medindo até $2,13 \mathrm{~m}$, com precisão de $0,1 \mathrm{~cm}$. A classificação foi feita conforme os pontos de corte para sexo e idade $\mathrm{WHO}$ $(2006,2007)$. As crianças com idade gestacional menor que 37 semanas tiveram suas idades corrigidas.

A partir destes dados, foram calculados os índices de massa corporal (IMC) e estatura/ comprimento por idade (IMC/I e E/I, respectivamente) para todas as crianças, além dos índices de peso/idade $(\mathrm{P} / \mathrm{I})$ para menores de 10 anos e peso por estatura/comprimento (P/E) para menores de 5 anos, todos classificados a partir dos padrões de referências específicos para o sexo da Organização Mundial de Saúde $(2006,2007)$, segundo os pontos de corte preconizados pelo Sistema de Vigilância Alimentar e Nutricional do Ministério da Saúde ${ }^{12,13}$.

As crianças classificadas como magreza ou magreza acentuada foram agrupadas como magreza quando $\mathrm{P} / \mathrm{E}$ e/ou IMC/I < percentil 3. As crianças classificadas como risco de sobrepeso, sobrepeso, obesidade e obesidade grave foram agrupadas na categoria excesso de peso, considerando-se os critérios do SISVAN 2008: crianças de 0 a 5 anos incompletos com P/E e/ou IMC/I entre p85 e p97 foram classificadas como risco de sobrepeso; > percentil 97<percentil 99,9 como sobrepeso; e > percentil 99,9 como obesidade; e crianças de 5 a 10 anos incompletos, IMC/I percentil 85 e percentil 97 foram classificadas como sobrepeso; entre percentil 97 e 99,9 como obesidade; e > percentil 99,9 como obesidade grave $^{14}$.

\section{Dados laboratoriais}

A análise do perfil bioquímico foi realizada mediante consulta aos exames de sangue realizados durante o período de internação, disponíveis nos prontuários clínicos. Foram avaliados os resultados do hemograma e de proteína C reativa (PCR), considerando-se os valores de normalidade específicos para a idade recomendados pela instituição hospitalar.

\section{Dados dietéticos}

Para coleta de dados alimentares, do período antes da internação, foi feita a avaliação do consumo alimentar das crianças por meio de entrevista com seus responsáveis, através da aplicação de um inquérito alimentar qualitativo e um questionário de frequência alimentar não validado, contendo os seguintes alimentos: frutas, hortaliças, leite e derivados, feijão, carne, guloseimas (sendo classificados neste item biscoitos recheados, balas, chicletes, refrigerantes, macarrão instantâneo e bebidas açucaradas) e água.

A análise da ingestão alimentar no período de internação foi realizada, através de um formulário padrão, contendo itens para anotação das refeições recebidas no hospital e
63

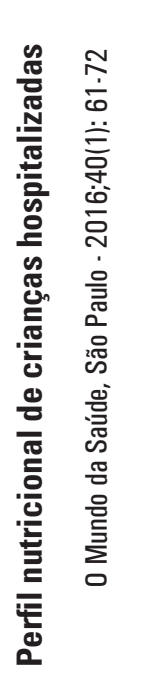


das suas respectivas quantidades consumidas no desjejum, colação, almoço, lanche da tarde e jantar. As crianças que tinham consumido menos da metade ou não havia consumido nada em pelo menos duas refeições oferecidas foram classificadas como baixa aceitação. Além do registro dos alimentos recebidos de fora hospital.

\section{Outras variáveis}

Foram coletados nos prontuários médicos informações pessoais, diagnóstico, data de internação e alta, dieta prescrita. Outras informações foram coletadas com a mãe ou responsável, como dados socioeconômicos, número de gestações, uso contínuo de medicamentos pela criança, medidas antropométricas do nascimento e informações sobre o aleitamento materno.

Os diagnósticos foram agrupados em icterícia neonatal, doenças respiratórias, doenças cardíacas, doenças gastrointestinais, correções cirúrgicas, crise convulsiva, doenças exantemáticas, infecções no trato urinário e complicações, desidratação, traumatismo crânio-encefálico e outras doenças (correspondendo àqueles diagnósticos em que

\section{RESULTADOS}

Participaram do estudo 208 crianças, sendo 128 meninos $(61,5 \%)$ e 80 meninas $(38,5 \%)$. A faixa etária variou de 3 dias a 12 anos, sendo que a mediana da idade foi de 21,5 (6-59) meses. Um percentual de $86,7 \%$ de crianças esteve internada em um período inferior a 7 dias. Dos motivos de internação diagnosticados no momento da coleta de dados, as doenças respiratórias foram as causas mais prevalente de internação $(33,2 \%)$, seguida das doenças gastrointestinais $(10,7 \%)$ e icterícia neonatal se encontrou menos de 2 casos).

O perfil de aleitamento materno foi coletado através de perguntas específicas quanto ao tempo de aleitamento materno exclusivo (AME), para aquelas que já não estavam em aleitamento materno exclusivo, e tempo de aleitamento materno total (AMT), para aqueles que já tinham desmamado, além disso coletouse dados de uso da mamadeira e composição desta.

\section{Análise estatística}

As análises estatísticas no programa Statistical Package for the Social Sciences ${ }^{\circledR}$ (SPSS, versão 20.0). As variáveis contínuas foram testadas quanto à sua normalidade mediante o teste de Kolmogorov-Smirnov. As variáveis foram descritas como mediana e intervalos interqualíticos $(25 / 75 \%)$ ou ainda como valor absoluto (percentual). As diferenças entre grupos para variáveis categóricas foram detectadas pela aplicação do teste de quiquadrado e para variáveis contínuas pela aplicação do teste de Kruskal Wallis seguido por LSD de Fisher (variáveis não-paramétricas). Um nível a menor que 5\% foi considerado significativo.

$(10,7 \%)$ (Tabela 1$)$.

Das crianças avaliadas, 43,7\% receberam AME em um período inferior a 2 meses, $60 \%$ amamentaram em um período inferior a 1 ano e $60,4 \%$ utilizava mamadeira, sendo as fórmulas infantis $(51,6 \%)$ e farinhas açucaradas $(42,2 \%)$ a composição mais consumida. A introdução de leite de vaca precoce (consumo antes dos 12 meses de idade) foi observada por $88,4 \%$ das crianças (Tabela 2).

Tabela 1. Caracterização das crianças internadas na pediatria de um hospital de ensino, Viçosa-MG, 2013-2014.

\begin{tabular}{lc}
\hline \multicolumn{1}{c}{ Variáveis } & $\mathbf{n}(\%)$ \\
\hline Idade (meses) & $21,5(6-59)^{*}$ \\
\hline Tempo de internação (dias) & \\
\hline $1-7$ & $157(86,7 \%)$ \\
\hline
\end{tabular}


...continuação - Tabela 1

\begin{tabular}{|c|c|}
\hline 8-14 & $16(8,8 \%)$ \\
\hline $15-30$ & $5(2,8 \%)$ \\
\hline $31-60$ & $3(1,7 \%)$ \\
\hline \multicolumn{2}{|l|}{ Diagnóstico principal } \\
\hline Doenças respiratórias & $62(33,2 \%)$ \\
\hline Doenças intestinais & $20(10,7 \%)$ \\
\hline Icterícia neonatal & $20(10,7 \%)$ \\
\hline Correções cirúrgicas & $17(9,1 \%)$ \\
\hline Crise convulsiva & $11(5,9 \%)$ \\
\hline Doenças exantemáticas & $10(5,3 \%)$ \\
\hline Doença cardíaca & $5(2,7 \%)$ \\
\hline Infecção no trato urinário e complicações & $4(2,1 \%)$ \\
\hline Desidratação & $3(1,6 \%)$ \\
\hline Traumatismo crânio-encefálico & $3(1,6 \%)$ \\
\hline Doenças endócrinas & $3(1,6 \%)$ \\
\hline Outras (doenças com $n \leq 2$ ) & $29(15,5 \%)$ \\
\hline \multicolumn{2}{|l|}{ Presença de anemia ** } \\
\hline Não & $127(74,3 \%)$ \\
\hline Sim & $44(25,7 \%)$ \\
\hline
\end{tabular}

*Valores expressos em mediana (p25-p75)

** Hemoglobina: Até 5 anos < 11 g/dL; 5 a 11 anos < 11,5 g/dL; 12 a 14 anos < 12 g/dL (OMS, 1985)15

Tabela 2. Características do nascimento e perfil de aleitamento materno de crianças internadas na pediatria de um hospital de ensino, Viçosa-MG, 2013-2014.

\begin{tabular}{lc}
\hline \multicolumn{1}{c}{ Variáveis } & $\mathbf{n}(\%)$ \\
\hline Peso ao nascer & $5(2,8 \%)$ \\
\hline Peso extremamente baixo (<1.000g) & $7(3,9 \%)$ \\
Baixo peso ao nascer (1.000 a 2.499g) & $52(28,9 \%)$ \\
Peso insuficiente (2.500 a 2.999g) & $114(63,3 \%)$ \\
Peso adequado (3.000 a 4.499g) & $2(1,1 \%)$ \\
Peso excessivamente grande (>4.500g) & \\
\hline Idade gestacional & $24(11,9 \%)$ \\
\hline Pré-termo (<37 semanas) & $175(87,1 \%)$ \\
À termo (37 a 41 semana) & $2(1,0 \%)$ \\
Pós-termo ( $\geq 42$ semanas) & \\
\hline Tempo AME (meses) & \\
\hline
\end{tabular}

continua... 
...continuação - Tabela 2

\begin{tabular}{lc}
\hline Nunca amamentou & $42(25,5 \%)$ \\
\hline $0-2$ meses & $30(18,2 \%)$ \\
$>2-6 m e s e s$ & $84(50,9 \%)$ \\
$>6$ meses & $9(5,5 \%)$ \\
\hline Tempo AMT (meses) & $35(38,9 \%)$ \\
\hline$<6$ meses & $19(21,1 \%)$ \\
6 -12 meses & $24(26,7 \%)$ \\
12-24 meses & $12(13,3 \%)$ \\
$>24$ meses & \\
\hline Uso de mamadeira (crianças menores 2 anos) & $42(39,6 \%)$ \\
\hline Não & $64(60,4 \%)$ \\
Sim & \\
\hline Composição da mamadeira (menores 2 anos) & $33(51,6 \%)$ \\
\hline Fórmulas infantis & $27(42,2 \%)$ \\
Farinhas açucaradas + Leite de vaca & $6(9,5 \%)$ \\
Outros & \\
\hline Idade de introdução do Leite de vaca (crianças & \\
menores 2 anos) & $48(69,6 \%)$ \\
\hline$<6$ meses & $13(18,8 \%)$ \\
$>$ 6-12 & $8(11,6 \%)$ \\
\hline Va meses &
\end{tabular}

Valores expressos em números absolutos (percentual).

Quanto ao estado nutricional das crianças internadas, 80\% foram classificadas como eutróficas $(n=152), 10 \%$ como magreza $(n=19), 6 \%$ como risco de sobrepeso $(n=11), 2 \%$ como sobrepeso $(n=4)$ e $2 \%$ como obesidade $(n=2)$ (Figura 1$)$.

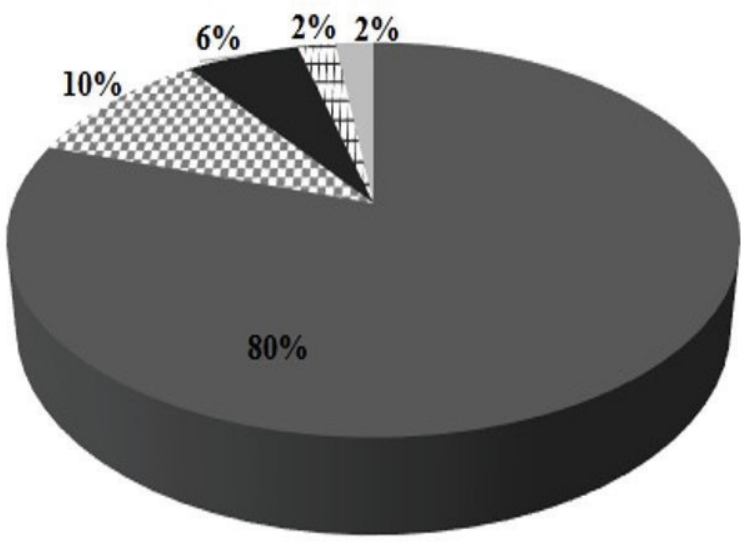

- Eutrofia

yagreza

- Risco de sobrepeso

+ Sobrepeso

- Obesidade

Figura 1. Classificação do estado nutricional das crianças internadas na pediatria de um hospital universitário, Viçosa-MG, 2013-2014. 
Ao comparar o estado nutricional com características clínicas e de aleitamento materno, verificou-se que o grupo classificado como magreza apresentou maior frequência de crianças com linfócito sérico reduzido.

A mediana do tempo de aleitamento materno exclusivo foi menor neste grupo quando comparado às crianças eutróficas e com excesso de peso (Tabela 3). A presença de alergia alimentar foi relatada em 5,4\% das crianças avaliadas. A maioria (50,7\%) não apresentava aversão alimentar, e, quando esta foi mencionada, o grupo mais citado foi o das hortaliças $(22,5 \%)$, seguido das frutas $(5,1 \%)$.

De acordo com a frequência do consumo de alimentos dos diferentes grupos alimentares observou-se que as guloseimas, as frutas e as hortaliças foram os grupos de consumo não diário mais frequente,68,9\%, 37,8\% e 35,2\%, respectivamente (Tabela 4). A quantidade de água consumida diariamente teve mediana de $450(250-700) \mathrm{ml}$.

Tabela 3. Associação entre estado nutricional e as variáveis de idade, tempo de internação, exames bioquímicos e tempo de aleitamento materno em crianças internadas em um hospital de ensino, Viçosa-MG, 2013-2014.

\begin{tabular}{|c|c|c|c|c|}
\hline Variáveis & $\begin{array}{c}\text { Magreza } \\
(n=19)\end{array}$ & $\begin{array}{l}\text { Eutrofia } \\
(n=152)\end{array}$ & $\begin{array}{c}\text { Excesso de peso } \\
(n=19)\end{array}$ & $\mathbf{P}$ \\
\hline Idade (meses) & $7,5(3,5-35)$ & $23,5(6-58,8)$ & $22(12,5-100)$ & 0,073 \\
\hline Tempo de internação (dias) & $4(2-7)$ & $3(2-5)$ & $3(2-6,25)$ & 0,312 \\
\hline Perda de peso no último mês & & & & 0,370 \\
\hline Não & $8(61,5 \%)$ & $81(69,2 \%)$ & $7(58,3 \%)$ & \\
\hline Sim & $5(38,5 \%)$ & $36(30,8 \%)$ & $5(41,7 \%)$ & \\
\hline Internações anteriores & & & & 0,693 \\
\hline Não & $9(50 \%)$ & $96(68,1 \%)$ & $12(70,6 \%)$ & \\
\hline Sim & $9(50 \%)$ & $45(31,9 \%)$ & $5(29,4 \%)$ & \\
\hline Hemoglobina $(11,5-13,3 \mathrm{~g} / \mathrm{dL})$ & & & & 0,122 \\
\hline Adequado & $15(93,8 \%)$ & $87(68,5 \%)$ & $13(76,5 \%)$ & \\
\hline Baixo & $1(6,2 \%)$ & $34(26,8 \%)$ & $4(23,5 \%)$ & \\
\hline Elevado & $0(0,0 \%)$ & $6(4,7 \%)$ & $0(0,0 \%)$ & \\
\hline Leucócito* $^{*}$ & & & & 0,391 \\
\hline Adequado & $5(29,4 \%)$ & $65(52,8 \%)$ & $9(52,9 \%)$ & \\
\hline Baixo & $1(5,9 \%)$ & $7(5,7 \%)$ & $0(0,0 \%)$ & \\
\hline Elevado & $11(64,7 \%)$ & $51(41,5 \%)$ & $8(41,1 \%)$ & \\
\hline Bastonetes $(0-200 \mathrm{n} \% / \mathrm{mm})$ & & & & 0,204 \\
\hline Adequado & $16(94,1 \%)$ & $118(92,9 \%)$ & $14(82,4 \%)$ & \\
\hline Elevado & $1(5,9 \%)$ & $9(7,1 \%)$ & $3(17,6 \%)$ & \\
\hline Linfócito (1500-7000nº/mm) & & & & 0,038 \\
\hline Adequado & $9(56,3 \%)$ & $103(85,1 \%)$ & $14(82,3 \%)$ & \\
\hline Baixo & $5(31,2 \%)$ & $17(14,1 \%)$ & $1(5,9 \%)$ & \\
\hline Elevado & $2(12,5 \%)$ & $1(0,8 \%)$ & $2(11,8 \%)$ & \\
\hline
\end{tabular}

continua... 
...continuação - Tabela 3

\begin{tabular}{lcccc}
\hline PCR $(\leq 6 \mathrm{mg} / \mathrm{dL})$ & & & 0,181 \\
\hline Adequado & $7(53,8 \%)$ & $42(38,5 \%)$ & $8(53,3 \%)$ & \\
Elevado & $6(46,2 \%)$ & $67(61,5 \%)$ & $7(46,7 \%)$ & 0,015 \\
\hline Tempo AME & $0,25(0,0-3,0)^{\mathrm{a}}$ & $4(0,25-6,0)^{\mathrm{b}}$ & $6(0,0-6,0)^{\mathrm{b}}$ & 0,063 \\
\hline Tempo AMT & $11(1,01-32)$ & $12(3-23)$ & $9(6-15)$ & \\
\hline
\end{tabular}

Valores expressos em mediana (p25-p75) ou em números absolutos (percentual). P: resultados das comparações entre os grupos por teste de Kruskall seguido LSD de Fisher (variáveis numéricas) ou quiquadrado (variáveis categóricas). Resultados em negrito expressam diferença significativa, sendo que letras distintas representam diferença entre os grupos $(p<0,05)$. Valores de referência utilizados para os exames bioquímicos expressos entre parêntese a frente do respectivo parâmetro.

${ }^{*}$ Valores de referência: 1-3 anos: 6000-11.000 no $/ \mathrm{mm}$; 3 a 5 anos: 4000-12000nº $/ \mathrm{mm}$; 6-11 anos: 3400-10800nº/mm; 12-15 anos: Masculino $3000-9100$ no $/ \mathrm{mm}$ e feminino 4100-8900 nº/mm.

AME - Aleitamento Materno Exclusivo.

AMT - Aleitamento Materno Total.

PCR - Proteína C-reativa

Tabela 4. Frequência do consumo de alimentos por crianças internadas na pediatria de um hospital de ensino, Viçosa-MG, 2013-2014.

\begin{tabular}{lc}
\hline \multicolumn{1}{c}{ Consumo diário } & $\mathbf{n}(\%)^{*}$ \\
\hline Frutas & $92(62,2 \%)$ \\
Nim & $56(37,8 \%)$ \\
\hline Hortaliças & $94(64,8 \%)$ \\
\hline Sim & $51(35,2 \%)$ \\
\hline Não & $121(82,9 \%)$ \\
\hline Leite e derivados & $25(17,1 \%)$ \\
\hline Sim & $109(76,2 \%)$ \\
\hline Não & $34(23,8 \%)$ \\
\hline Carne & \\
\hline Sim & $134(91,8 \%)$ \\
Não & $12(8,2 \%)$ \\
\hline Feijão & \\
\hline Sim & $42(31,1 \%)$ \\
\hline Não & $93(68,9 \%)$ \\
\hline Guloseimas & \\
\hline Sim & \\
\hline
\end{tabular}

*Valores expressos em números absolutos (percentual). 
Em relação à ingestão alimentar no período de internação, foi apresentado na figura 2 a frequência dos tipos alimentares prescritos, sendo a dieta livre a mais frequente. Entretanto quando comparado o tipo de dieta prescrita com a aceitação não foi evidenciado diferença $(p=0,230)$.

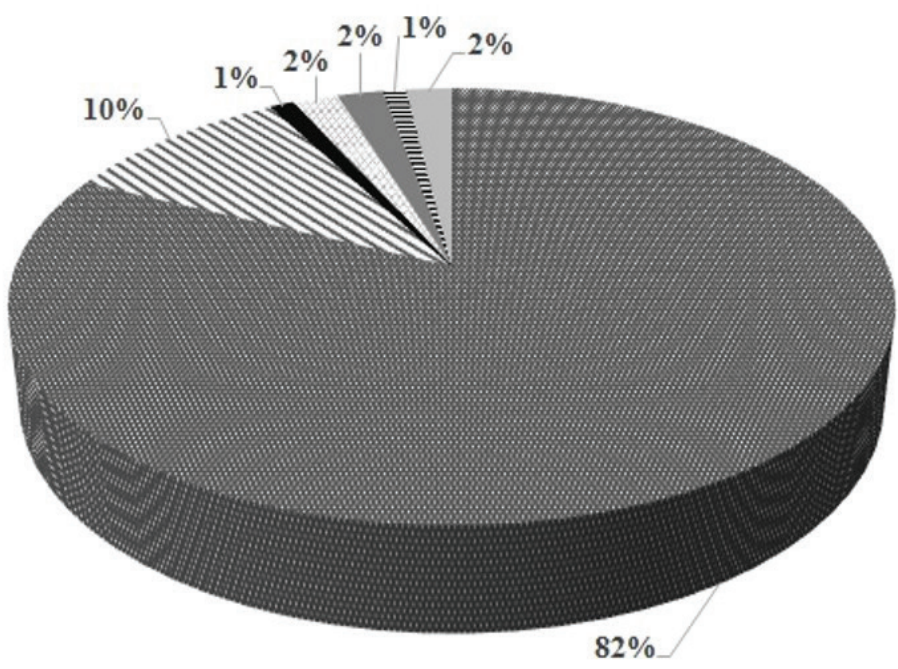

Dieta livre para

idade

$\therefore$ Dieta branda

Dieta liquida

Dieta zero

- Dieta especifica

para diabético

=Dieta hipossódica

Dieta laxativa

Figura 2. Distribuição do percentual de dietas prescritas na pediatria de um hospital universitário, 2013 a 2014.

Foi observado ainda uma menor aceitação das refeições oferecidas pelo hospital por aquelas crianças com PCR elevado ( $p=0,034)$ e leucócito elevado $(p=0,040)$ (Tabela 5).

Tabela 5. Aceitação da dieta prescrita e concentração sérica de marcadores inflamatórios em crianças internadas em um hospital de ensino, Viçosa-MG, 2013-2014.

\begin{tabular}{lccc} 
Marcadores inflamatórios & Aceitação & P & \\
\hline & Boa & & 0,034 \\
\hline PCR & $22(71 \%)$ & $9(29 \%)$ & \\
\hline Adequado & $29(47,5 \%)$ & $32(52,5 \%)$ & 0,040 \\
\hline Elevado & $28(70 \%)$ & $2(30 \%)$ & \\
\hline Leucócito & $3(60 \%)$ & $30(50,8 \%)$ & 0,124 \\
\hline Adequado & $29(49,2 \%)$ & & \\
\hline Baixo & & $33(38,8 \%)$ & \\
\hline Elevado & $52(61,2 \%)$ & & \\
\hline Linfócito & & & \\
\hline Adequado & & & \\
\hline
\end{tabular}

continua... 
...continuação - Tabela 5

\begin{tabular}{lccc}
\hline Baixo & $7(43,8 \%)$ & $9(59,2 \%)$ & \\
\hline Elevado & $1(33,3 \%)$ & $2(66,7 \%)$ & 0,878 \\
\hline Bastonetes & & & \\
\hline Adequado & $53(57 \%)$ & $40(43 \%)$ & \\
Elevado & $6(54,5 \%)$ & $5(45,5 \%)$ & \\
\hline
\end{tabular}

Valores expressos em números absolutos (percentual). p:resultados das comparações entre os grupos experimentais pelo teste do qui-quadrado. Resultados em negrito expressam diferença significativa entre os grupos $(\mathrm{P}<0,05)$

\section{DISCUSSÃO}

O presente estudo avaliou as características das crianças e adolescentes internados na pediatria de um hospital visando o diagnóstico de risco nutricional, bem como fatores que possam influenciar o estado nutricional e o consumo alimentar durante o período de hospitalização.

Neste contexto, nossos resultados evidenciaram as doenças respiratórias como a maior causa de internação das crianças $(30,2 \%)$, seguidas das doenças gastrointestinais e icterícia neonatal. Estes resultados se assemelham aos observados por Sarni et $\mathrm{al}^{1}$ em um estudo nas enfermaria pediátrica de 10 hospitais universitários ou de ensino de 4 regiões geográficas do país (Nordeste, Sudeste, Centro-oeste, Sul), os principais diagnósticos de internação foram as doenças do sistema respiratório e as doenças diarreicas, as quais são agravadas em crianças desnutridas. Magalhães et al. ${ }^{16}$ também evidenciaram em seu estudo com crianças internadas, em um hospital universitário na cidade do Rio de Janeiro, que as doenças respiratórias eram o motivo principal de internação de crianças (29,5\%).

Quanto às características de aleitamento materno, Schwartz et al. ${ }^{17}$ encontraram, em uma unidade de internação pediátrica e ambulatório geral de pediatria, $31,8 \%$ de AME em um tempo menor que 4 meses, $67,4 \%$ de leite complementado, sendo leite de vaca associado a outro ingrediente o mais consumido $(37,9 \%)$ seguido da fórmula infantil $(35,8 \%)$. Outro estudo verificou $62,4 \%$ das crianças faziam uso de leite de vaca antes dos 6 meses e o consumo de fórmulas infantis foi de $23 \%$ das crianças menores de seis meses ${ }^{18}$. No presente estudo, evidenciou-se um maior percentual de 43,7\% de AME em um tempo inferior a 2 meses, já o uso de leite de vaca associado a farinhas açucaradas foi de $42,2 \%$, somado a oferta precoce (antes de 1 ano) de leite materno em $88,4 \%$. O Ministério da Saúde recomenda o aleitamento materno exclusivo até os 6 meses, o mantendo até no mínimo 2 anos, bem como o de leite de vaca não é indicado antes do primeiro ano de vida da criança ${ }^{19}$. A introdução precoce do leite de vaca pode estar associada a quadro de anemias, além de ser um alimento alergênico ${ }^{18}$.

As menores medianas do tempo de aleitamento materno exclusiva encontradas entre as crianças classificadas como magreza também foram observadas no estudo de Alves et al. $^{20}$, que destaca o fato de crianças em aleitamento materno apresentarem ganho de peso significantemente maior. Uma explicação possível seria relacionada às propriedades do leite materno, já que este possui ação antiinfecciosa e melhor aceitação por parte do filho $^{20}$. Outro aspecto a ser considerado é a associação positiva encontrada entre o menor tempo de aleitamento materno em crianças nascidas com baixo peso, característica que pode afetar na evolução do estado nutricional da criança ${ }^{21}$.

A prevalência de desnutrição no âmbito hospitalar tem sido evidenciada por muitos estudos realizados, como o Ferreira et al. ${ }^{22}$, em 2002, que encontraram $71,2 \%$ de crianças desnutridas no momento da admissão. No entanto o presente estudo revelou uma 
prevalência menor de magreza (10\%), assemelhando com resultados de estudos mais recentes que demonstram frequências que variam de $14,7 \% 22$ a $18,8 \%$ de magreza $^{16}$. O percentual de excesso de peso observado $(10 \%)$ foi inferior ao estudo de Magalhães et al. ${ }^{16}$, onde evidenciou $22.5 \%$ de excesso de peso entre as crianças hospitalizadas.

Em relação aos dados bioquímicos, observouse que $25,7 \%$ das crianças eram anêmicas, um resultado inferior ao encontrado por Magalhães et al. ${ }^{16}$, de $54,8 \%$ das crianças hospitalizadas estudadas com anemia. Apesar de inferior, este resultado alerta para a importância da investigação e tratamento da anemia no ambiente hospitalar.

Quanto aos outros parâmetros bioquímicos evidenciaram-se associações relevantes. A diminuição do número de linfócitos, denominada linfocitopenia, é uma resposta à ativação do eixo hipófise/suprarrenal, que pode ocorrer no estresse de qualquer origem, sendo produzidas por um grande número de doenças, como as infecciosas/inflamatórias ${ }^{24}$. A linfocitopenia observada mais frequente em crianças abaixo do peso pode ser explicada pela interação entre infecção e desnutrição já reconhecida, sendo o linfócito um componente do sistema imunológico e a desnutrição um fator que facilita a instalação de processos infecciosos, assim como a infecção pode também comprometer o estado nutricional até mesmo por prejudicar a ingestão alimentar ${ }^{4}$.

O comprometimento da ingestão alimentar

\section{CONCLUSÃo}

Os resultados do presente estudo indicam uma maior prevalência de crianças hospitalizadas eutróficas. Entretanto, foi identificado um impacto negativo no consumo alimentar em crianças que apresentaram alterações do estado inflamatório, bem como associação entre a linfocitopenia e o baixo peso, além da associação entre o déficit ponderal e o menor tempo de aleitamento materno exclusivo.

Assim, considerando que a baixa ingestão aumenta o risco de desnutrição e as consequências desta a curto e a longo prazo, ressalta-se que os fatores que influenciam no durante a hospitalização pode ter vários fatores interferentes, como o próprio processo patológico e o ambiente hospitalar ${ }^{25}$. No presente estudo observou-se a influência do processo patológico ao se evidenciar uma pior aceitação pelas crianças que apresentavam leucocitoses e elevação do PCR, indicadores de resposta inflamatória que podem relacionar-se à falta de apetite ${ }^{26}$. O horário e características das refeições servidas (temperatura, odor) são, ainda, citados como fatores que influenciam na aceitação das refeições no ambiente hospitalar ${ }^{25}$.

As frutas e hortaliças foram os grupos dos alimentos saudáveis que apresentaram maior percentual do consumo não diário. Semelhante a outro estudo, no qual se verificou que as verduras de folhas e legumes eram os alimentos menos consumidos diariamente por crianças de 2 a 5 anos, mas que identificou maior consumo diário de frutas $(43,8 \%)$ que o observado em nosso estudo ${ }^{27}$. Tal resultado demonstra que a alimentação infantil é uma questão a ser trabalhada, já que a ingestão de insuficiente de alimentos de qualquer grupo alimentar pode comprometer o fornecimento adequado de nutrientes. Ao considerarmos especificamente o baixo consumo de frutas e hortaliças, reconhecemos o possível comprometimento do aporte adequado dos micronutrientes, os quais apresenta influência negativa na resposta do sistema imunológico na infecção da criança, um aspecto ainda mais importante ao considerarmos o cenário hospitalar ${ }^{27,28}$.

o estado nutricional, como o aleitamento materno adequado, devam ser trabalhados de forma eficaz. Assim, como as crianças que apresentem alterações de PCR e leucocitose devam receber atenção específica no âmbito hospitalar para prevenir e minimizar os efeitos da desnutrição.

Mais estudos que aprimorem os métodos de avaliação nutricional em crianças hospitalizadas, bem como avaliem fatores associados à sua baixa ingestão alimentar intra-hospitalar são necessários para progredir no cuidado de tal população.

\section{1}

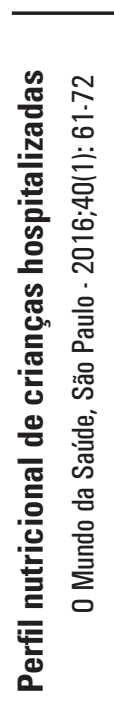




\section{REFERÊNCIAS}

1. Sarni ROS, Carvalho MFCC, Monte CMG, Albuquerque ZP, Souza FIS. Avaliação antropométrica, fatores de risco para desnutrição e medidas de apoio nutricional em crianças internadas em hospitais de ensino no Brasil. J. Pediatri. (Rio J.). 2009; 85 (3):223-8.

2. Silva CCSP. Força da preensão da mão como método de rastreio de desnutrição em crianças e adolescentes internadas, [Dissertação de mestrado em Nutrição Clínica]. Porto: Faculdade de Ciências da Nutrição e Alimentação, Universidade do Porto; 2012. 31p.

3. Carvalho FC, Lopes CR, da Costa Vilela L, Vieira MA, Rinaldi AEM, Crispim CA. Tradução e adaptação cultural da ferramenta Strongkids para triagem do risco de desnutrição em crianças hospitalizadas. Rev Paul Pediatr. 2013; 31 (2):159-65.

4. Ferraz LF, Viriato A, De Moura A. Análise do diagnóstico nutricional de pacientes em assistência hospitalar de infectologia. Mundo Saúde. 2013; 37(3):253-8.

5. Oliveira AF, Oliveira FLC, Juliano Y, Ancona-Lopez F. Evolução nutricional de crianças hospitalizadas e sob acompanhamento nutricional. Rev. Nutr. 2005; 18( 3 ): 341-8.

6. Azevedo LC, Medina F, Silva AA, Campanella ELS. Prevalência de desnutrição em um hospital geral de grande porte de Santa Catarina/Brasil. Arquivos Catarinenses de Medicina. 2006; 35 (4): 89-96.

7. Kanashiro M, Péret LA, Penna FJ, Fujii JB. Avaliação pondo-estatural e condições para esta aferição em crianças internadas em hospitais de Belo Horizonte. Revista Médica de Minas Gerais 2008; 18 (3): 153-9.

8. Barbosa-Silva MCG, Barros AJD. Avaliação nutricional subjetiva: Parte 2 - Revisão de suas adaptações e utilizações nas diversas especialidades clínicas. Arq. Gastroenterol. 2002; 39( 4 ): 248-252.

9. Bousquet LA, Stringhini MLF, Mortoza AS. Avaliação nutricional subjetiva global: instrumentos para triagem em crianças hospitalizadas. Rev. Aten. Saúde., são caetano do sul, 2016, 14 (47): 67-74.

10. Da Silva EP, Tiengo A. Perfil Nutricional de Crianças Hospitalizadas e sua Relação com o Período de Internação em um Hospital de Ensino no Sul de Minas Gerais. Rev. Ciências em Saúde, 2015, 4 (4): 61-72.

11. Dornelles CTL, Silveira C, Cruz LB, Refosco L, Simon M, Maraschin T. Protocolo de atendimento e acompanhamento nutricional pediátrico por níveis assistenciais. Rev HCPA. 2009;29(3):229-38.

12. Organização Mundial da Saúde. WHO child growth standards: length/height-for-age, weight-forage,weight-for-length, weight-forheight and body mass index-for-age: methods and development.Geneva: WHO; 2006.

13. Organização Mundial de Saúde. de Onis M, Onyango AW, Borghi E, Siyam A, Nishida C, Siekmann J. Development of a WHO growth reference for school-aged children and adolescents. Bulletin of the World Health Organization. 2007; 85: 660-667.

14. Brasil. Ministério da Saúde. Protocolo do Sistema de Vigilância Alimentar e Nutricional-SISVAN na assistência à saúde. Brasília, DF: Ministério da Saúde; 2008.

15. Demayer EM, Adies-Tegman M. The prevalence of anaemia in the world. World Health Statistics Quartely.1985; 38: 302-16

16. Magalhães EA, Martins MA, Rodrigues CC, Moreira AS. Associação entre o tempo de internação e a evolução do estado nutricional de crianças internadas em um hospital universitário. Demetra. 2013; 8(2):103-14.

17. Schwartz R, Carraro JL, Riboldi BP, Behling EB (2012). Associação entre aleitamento materno e estado nutricional atual de crianças e adolescentes atendidos em um hospital do sul do Brasil. Rev HPCA. 2012; 32(2):147-53.

18. Bortolini GA, Vitolo MR, Gubert MB, Santos LMP. Consumo precoce de leite de vaca entre crianças brasileiras: resultados de uma pesquisa nacional. J Pediatr (Rio J). 2013; 89 (6): 608-13.

19. Brasil. Ministério da Saúde. Secretaria de Atenção à Saúde. Departamento de Atenção Básica. Dez Passos para uma alimentação saudável: guia alimentar para menores de dois anos. Um guia para o profissional da saúde na atenção básica. Brasília: Ministério da Saúde; 2010. 72p. (Serie A. Normas e Manuais Técnicos).

20. Alves JGB, Filho JEC, Figueiroa JN. Avaliação Nutricional de Lactentes Hospitalizados. Rev Esc Enf Usp. $2001 ; 35$ (1): 60-4.

21. Chaves RG, Lamounier JA, César CC. Fatores associados com a duração do aleitamento materno. J. Pediatr. (Rio J.). $2007 ; 83$ (3): 241-6.

22. Ferreira HS, França AO. Evolução do estado nutricional de crianças submetidas à internação hospitalar. J Pediatr. 2002; 78(4), 491-6.

23. Silveira CRM. Evolução do estado nutricional dos pacientes internados na unidade pediátricas do hospital de clínicas de Porto Alegre, [Dissertação de mestrado em Ciências Médicas: Pediatria]. Porto Alegre: Faculdade de Medicina, Universidade Federal do Rio Grande do Sul; 2007. 126p.

24. Failace R, Fernandes FB, Failace R. Hemograma. Manual de interpretação. 5aㅗ edição. Porto Alegre: Ed. Artmed; 2009.424 p.

25. Prieto DB, Leandro-Merhi VA, Mônaco DV, Lazarini ALG. Intervenção nutricional de rotina em pacientes de um hospital privado. Rev Bras Nutr Clin. 2006; 21(3): 181-7.

26. Oliveira FLCO. Avaliação do estado nutricional- Avaliação Bioquímica. In: Silva SMCS, Mura JDP. Tratado De Alimentação, Nutrição e dietoterapia. $2^{\mathrm{a}}$ edição. São Paulo: Roca; 2010. p. 157-61.

27. Muniz N, Ludmila C, Vieira MFA. Consumo alimentar entre crianças brasileiras de dois a cinco anos de idade: Pesquisa Nacional de Demografia e Saúde (PNDS), 2006. Ciênc. Saúde coletiva. 2013; 18 (11): 3369-77.

28. Macedo EMC, Amorim MAF, Silva ACS, Castro CMMB. Efeitos da deficiência de cobre, zinco e magnésio sobre o sistema imune de crianças com desnutrição grave. Rev Paul Pediatr. 2010; 28 (Supl. 3):329-36.

Recebido em 10 de setembro de 2014. Aprovado em 20 de janeiro de 2016. 